\title{
Bazı Nar Çeşitlerinde Farklı Çiçek Tiplerinin Çiçek Tozu Çimlenme Gücünün Belirlenmesi
}

\author{
Meryem Gülce Aytan ${ }^{1 *}$, Hakan Engin ${ }^{2}$ \\ ${ }^{1}$ Çanakkale Onsekiz Mart Üniversitesi, Fen Bilimleri Enstitüsü, Bahçe Bitkileri ABD \\ ${ }^{2}$ Çanakkale Onsekiz Mart Üniversitesi, Ziraat Fakültesi, Bahçe Bitkileri Bölümü
}

16.11.2018 Geliş/Received, 14.03.2019 Kabul/Accepted

\section{Özet}

$\mathrm{Bu}$ çalışma bazı nar çeşitlerinde farklı çiçek tiplerinin çiçek tozu çimlenme gücünün belirlenmesi amaciyla, Çanakkale Onsekiz Mart Üniversitesi Dardanos Yerleşkesi nar bahçesinde yer alan 'Mayhoş 8', 'Katırbaşı', 'Yufkakabuk' ve 'Aşınar' çeşitlerinde yürütülmüştür. Nar ağaçlarında fizyolojik erkek morfolojik olarak erdişi steril çiçekler ve morfolojik ve fizyolojik yapıda fertil çiçekler bulunmaktadır. Bazı durumlarda çevresel faktörlere ve yetiştirme koşullarına göre nar ağaçlarında ara form çiçekler de görülmektedir. Verimi etkileyen en önemli faktörlerden biri steril ve fertil çiçek tozlarının çimlenme gücü yeteneğidir. Dört farklı nar çeşidinin steril, fertil ve ara form çiçek tiplerinin çiçek tozu çimlenme güçleri saptanmıştır. Çiçek tozu çimlenme gücü in vitro koşullarda agar-petri yöntemi ile belirlenmiştir. Çeşitler arası çiçek tozlarının çimlenme yeteneği ve çiçek yapıları arasındaki çiçek tozu çimlenmesi karşılaştırılmıştır. Çeşitler arası çiçek tozu çimlenme ortalamasında büyük bir fark olmadığı belirlenmiştir. 'Mayhoş 8' çeşidinin çimlenme ortalaması en yüksek \%20,8 olarak kaydedilmiştir. Steril çiçeklerin çimlenme yeteneğinin, ara form ve fertil çiçeklerin çimlenme yeteneğinden fazla olduğu belirlenmiştir. Steril çiçeklerin çiçek tozu çimlenme oranlarının iyi bir meyve tutumu için yeterli olmadığ belirlenmiştir.

Anahtar Kelimeler: çiçek tipleri, çiçek tozu çimlenmesi, punica granatum L.

\section{Determination of Germination Capability of Pollen in Different Flower Types in Some Pomegranate Varieties}

\begin{abstract}
In the pomegranate trees, there are hermaphroditic bisexual flowers and functionally male flowers. In some cases, intermediate forms are seen in pomegranate trees according to environmental factors and growing conditions. One of the most important factors affecting the fertility is the hermaphroditic bisexual flowers and functionally male flowers that ability of the germination capability of pollen. This study was carried out with the 'Mayhos 8', 'Katırbaşı', 'Yufkakabuk' and 'Aşınar' varieties in the pomegranate orchard in the Dardanos Campus of Çanakkale Onsekiz Mart University in order to determine the germination capability of different flower types. Four different pomegranate varieties of hermaphroditic
\end{abstract}

*Sorumlu Yazar (Corresponding Author): Meryem Gülce Aytan

(e-posta:m.gulce.aytan@gmail.com)

Bu makale Meryem Gülce Aytan'ın tez konusu kapsamında yazılmıştır. 
bisexual flowers, functionally male flowers and intermediate form of flowers pollen germination ratios were determined. The germination of the pollens in three types of flowers was determined by agar-petri method under in vitro condition. The germination ability of the pollens in four cultivars and the germination ratios of the three flowers types were compared. It was determined that the there was no significant difference in the germination average between varieties. The average germination rate of 'Mayhoş 8' was the highest with \%20,8. It was determined that functionally male flowers had more germination ability than intermediate form and hermaphroditic bisexsual flowers. It was determined that germination rates of functionally male flowers were insufficient for fruit set.

Keywords: flower types, pollen germination, punica granatum $\mathrm{L}$.

\section{Giriş}

Nar tarihte farklı kültür ve medeniyetlerin simgesi olmuş önemli bir meyvedir. Eski zamanlarda kültüre alındığı, bitkinin her türlü organından yararlanıldığ 1 özellikle çiçek ve meyvesinin farklı alanlarda ve amaçlarda kullanıldığı kaynaklarda belirtilmiştir (Gözlekçi ve Kaynak, 2000).

Nar (Punica granatum L.) andromonoik bitki türleri içinde yer alan, fertil (hermafrodit) ve steril (erkek) olarak iki tipte çiçek yapısındadır. Steril çiçekler A tipi, fertil çiçekler B tipi şeklinde adlandırılır (Engin ve Hepaksoy, 2003). Morfolojik olarak erdişi fizyolojik olarak erkek yapıdaki çiçekler steril (A tipi) çiçeklerdir. Bu yapıdaki çiçeklerde dişi organ fonksiyonel değildir. Steril çiçeklerin stamenleri fonksiyonel olduğundan tozlanmayı sağlar (Wetzstein ve ark., 2011). Erkek çiçeklerin görünümü V şeklini andırır ve yumurtalık yeterince gelişmemiştir. Tozlanmayı sağlayan bu çiçekler açıldıktan sonra dökülürler. Nar ağaçlarında genellikle steril çiçek sayısı fertil çiçek sayısına göre daha fazladır. Bu da verimi etkileyen en önemli faktörlerden biridir. Nar ağaçlarında fazla sayıda A tipi çiçek bulunması verimi düşürebilir (Wetzstein ve ark., 2011). Morfolojik ve fizyolojik yapıda olan meyve bağlayan çiçekler fertil (B tipi) çiçeklerdir (Varasteh ve Arzani, 2009). Fertil çiçekler tomurcuk halinde iken şişkin ve iri yapıdadır. Fertil çiçekler gelişmeye devam ettikçe boğumlu yapısıyla bir vazo şeklini andırır, ayrıca steril çiçeklere göre daha büyüktür.

Çevresel faktörlere, yetiştirme koşullarına ve çeşitlere göre bazı durumlarda nar ağaçları steril, erkek ve ara form olarak 3 çiçek tipini içerebilir. Ara formlar fertil çiçekler kadar iri yapıda ve tam şekil tanımına uymasa da meyve bağlayabilen çiçek tipleridir. Literatür araştırmalarına bakıldığında nar çiçek tipleri, çiçek yapıları ve polen çimlenmeleri üzerine yapılan çalışmaların az olduğu gözlemlenmiştir (Malgarejo ve ark., 2000). Bu gözlem son yıllarda yapılan çalışmaların nar üzerine yoğunlaşmasında etkili olmuştur. Genellikle farklı türlerde yapılan çalışmalar uygun ortamlarda polen çimlendirme ve büyüme düzenleyicilerin polen çimlenme üzerine etkilerini belirlemeye yönelik araştırmalardır. Çiçek tozu çimlenmesi üzerine farklı meyve türlerinde çalışmalar yapılmıştır. Kirazlar üzerinde yapılan bir çalışmada büyümeyi düzenleyici maddelerden olan brassinosteroidlerin polenlerin tüp uzaması üzerine etkisi olduğu ancak polen çimlenmesi üzerine etkili olmadığ 1985). Gökbayrak ve Engin (2015), asma kültür çeşitlerinde yapılan bir çalışmada epibrassinolidin polen çimlenmesini NAA'ya göre daha çok indüklediğini belirlemişlerdir. Zeytin polenlerinin çimlenmesinde $\mathrm{GA}_{3}{ }^{\prime}$ ün in vivoda olumlu etkisi olduğu Viti ve ark. (1990) tarafından saptanmıştır. 
$\mathrm{Bu}$ çalışma, 4 farklı nar çeşidinde verimliliği etkileyen en önemli faktörden biri olan çiçek yapılarının (steril, fertil ve ara form) polen çimlenme güçlerini tespit etmek amacıyla yapılmıştır.

\section{Materyal ve Yöntem}

Çalışmada kullanılan bitki materyali Çanakkale Onsekiz Mart Üniversitesi Dardanos Yerleşkesinde yer alan nar deneme ve araştırma parselinden temin edilmiştir. Bu çalışma doğrultusunda 'Mayhoş 8', 'Katırbaşı', 'Aşınar' ve 'Yufkakabuk' nar çeşitlerinin çiçekleri kullanılmıştır.

\section{1. Çiçek Tozunun Elde Edilmesi}

Çalışmada kullanılan 4 farklı çeşide ait nar ağaçlarının farklı yön ve yükseklikteki dallarında açmak üzere olan çiçeklerin tipleri incelenmiştir. Belirlenen çiçek tipleri toplanarak özel yalıtımlı çanta ile laboratuvara getirilmiştir. Elde edilen çiçekler çiçek tiplerine göre steril, fertil ve ara form olmak üzere ayrılmıştır. Ayrımı yapılan her çiçek tipindeki çiçeklerin anterleri pens yardımıyla koparılarak petri kaplarına alınmış ve $25^{\circ} \mathrm{C}$ de yaklaşı 24 saat bekletilerek polen salımı sağlanmıştır.

\section{2. Çiçek Tozu Çimlendirme Testleri}

In vitro da çiçek tozu çimlenme güçlerinin tespitinde agar-petri yöntemi kullanılmıştır (Eti, 1991). Çimlendirme ortamı, $100 \mathrm{ml}$ kaynayan saf suya $1 \mathrm{~g}$ agar ve $20 \mathrm{~g}$ şeker ilave edilerek elde edilmiştir (Engin ve ark., 2015). Hazırlanan besi ortamı, petri kaplarına 2 mm kalınlıkta tam soğuma gerçekleşmeden dökülmüştür. Çiçek tozlarının ekimi bir firça yardımıyla homojen şekilde dağılması sağlanarak gerçekleştirilmiştir (Şekil 2.1). Çimlenme sürecinde ihtiyaç olan nemi sağlamak amacıyla petri kaplarının üstlerine saf suyla 1slatılmış iki kat filtre kağıdı yerleştirilerek kapatılmıştır. Uygun nem sağlanan petriler $25^{\circ} \mathrm{C}$ de 24 saat çimlenmesi için bekletilmiştir. Çimlenme oranları, mikroskop (Olympus CX-41, Tokyo, Japonya) altında sayımları yapılarak belirlenmiştir. Bu belirleme işlemi, her petri kabında 3 bölgede sayımlar yapılarak tespit edilmiştir. Yapılan sayımlar sonucunda polen tüpü oluşturan ve oluşturmayan çiçek tozlarının oranı yüzde (\%) olarak belirlenmiştir (Şekil 2.2).

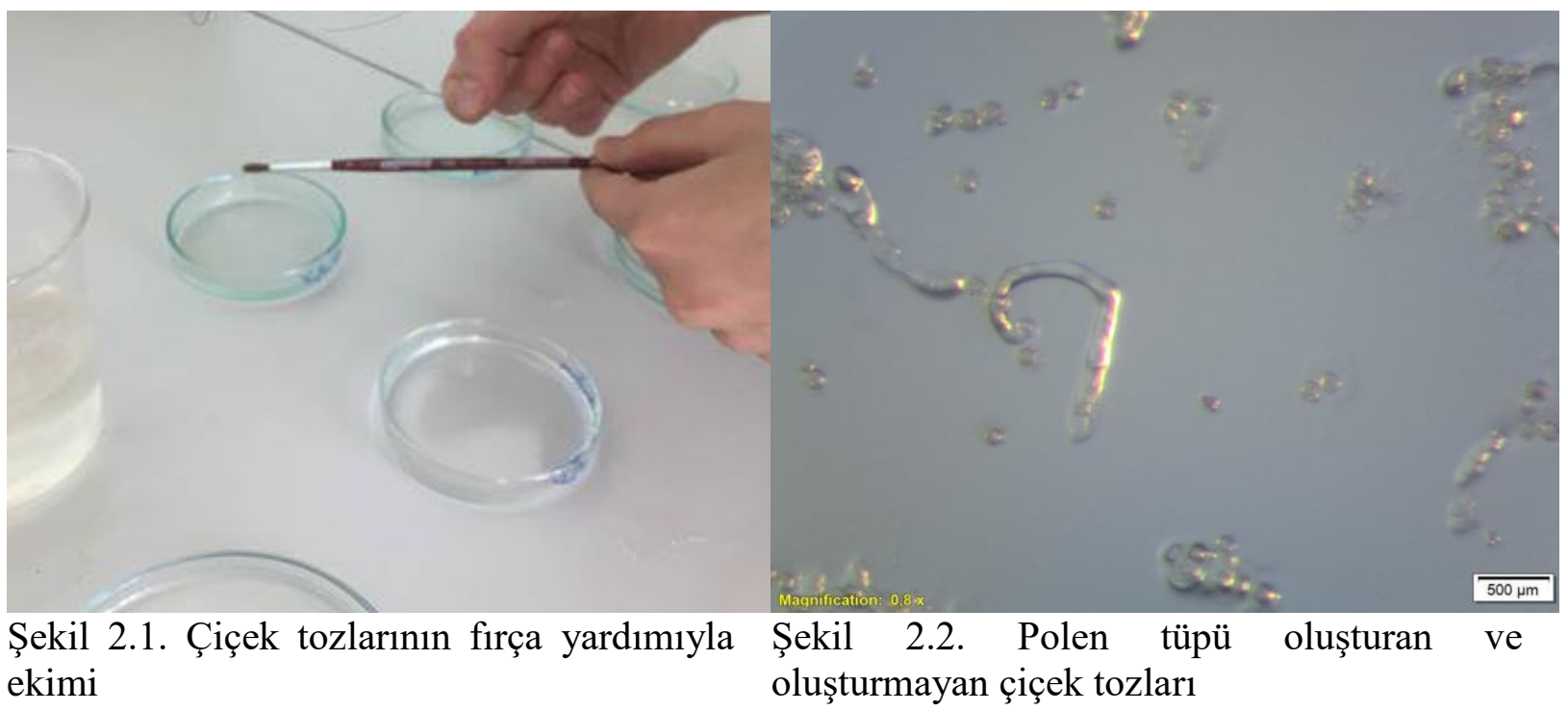




\section{3. İstatistiksel Analizler}

Çalışmada elde edilen veriler Minitab istatistik paket programı kullanılarak varyans analizine tabi tutulmuş farklılıklar Tukey $(\mathrm{P} \leq 0,05)$ çoklu karşılaştırma testi ile belirlenmiştir.

\section{Bulgular ve Tartışma}

'Mayhoş 8', 'Katırbaşı', 'Aşınar' ve 'Yufkakabuk' çeşitlerinin çiçek tozu çimlenme oranları Çizelge 3.1'de verilmiştir. Çeşitler arası ortalama çiçek tozu çimlenme oranı $\% 15,5$ ile $\% 20,8$ arasında değişmiştir. Çimlenme oranı ortalaması en yüksek çeşit \%20,8 ile 'Mayhoş 8' olup sırası ile \%19,2 'Aşınar', \%18,4 'Katırbaşı' ve en düşük çimlenme oranı ile \%15,5 'Yufkakabuk' çeşidinde belirlenmiştir.

Çiçek tiplerinin çiçek tozu çimlenme sonuçlarına bakıldığında ortalama en yüksek çimlenme oranı steril çiçeklerde görülmüştür. Fertil çiçeklerin ortalama çiçek tozu çimlenmesi \%18,7, ara formların ise \%10,6 olmuştur. Ara form çiçek tozu çimlenme ortalaması çiçek tipleri arasında en düşük olarak belirlenmiştir. 'Mayhoş 8', 'Yufkakabuk' ve 'Aşınar' çeşitlerinin ara formlarının çimlenme oranlarının fertil çiçeklere göre düşük olduğu saptanmıştır. Sadece 'Katırbaşı' çeşidinde ara form çiçek tozlarının çimlenme yüzdesi, fertil çiçeklerden fazla olduğu belirlenmiştir. Çimlenme oranlarının, fertil çiçekler, steril çiçekler ve ara formlar arasında istatistiki olarak farklı olduğu saptanmıştır.

'Mayhoş 8' çeşidi fertil çiçekler arasında \%26,1 ile çiçek tozu çimlenme oranı en yüksek çeşittir. 'Yufkakabuk' çeşidinin steril ve ara form çiçek tozları en düşük çimlenme yüzdesine sahip çiçeklerdir. Ara form çiçeklerde en yüksek çimlenme oranı 'Katırbaşı' çeşidinde saptanmıştır. Fertil çiçek ile ara form çiçeklerin çiçek tozu çimlenme oranı arasındaki en yüksek fark 'Mayhoş 8' çeşidine aittir. 'Katırbaşı' çeşidi steril çiçekler arasında en yüksek çiçek tozu çimlenme oranına sahip çeşit olup, fertil çiçek çimlenme oranı \%10,8 ile son sırada olduğu belirlenmiştir. Aşınar çeşidine ait steril çiçeklerin tozları çimlenme oranı olarak ikinci en yüksek çimlenme oranına sahip çeşittir. Steril çiçeklerin çiçek tozu çimlenme oranının $\% 26,1$ ile fertil ve ara form çiçeklerin çiçek tozu çimlenme yüzdelerinden fazla olduğu belirlenmiştir.

Çizelge 3.1. İncelenen dört çeşide ait dişi, ara form ve erkek çiçeklerinden elde edilen çiçek tozlarının çimlenme oranları \%

\begin{tabular}{|l|l|l|l|l|}
\hline \multirow{2}{*}{ Çeşit } & \multicolumn{3}{|c|}{ Farkl yapı1daki çiçek tipleri } & \multirow{2}{*}{ Ortalama } \\
\cline { 2 - 4 } & Fertil & Ara form & Steril & \\
\hline Mayhoş 8 & $26,11 \pm 2,54$ & $11,37 \pm 2,48$ & $24,89 \pm 9,4$ & $20,8 \pm 3,86$ \\
Yufkakabuk & $15,59 \pm 2,01$ & $8,06 \pm 2,24$ & $22,73 \pm 5,24$ & $15,5 \pm 2,74$ \\
Aşınar & $22,29 \pm 3,58$ & $9,96 \pm 2,54$ & $25,41 \pm 3,24$ & $19,2 \pm 2,84$ \\
Katırbaş1 & $10,76 \pm 1,69$ & $12,93 \pm 0,43$ & $31,36 \pm 3,84$ & $18,4 \pm 3,49$ \\
Ortalama & $18,69 \pm 2,09 \mathrm{~B}$ & $10,58 \pm 1,05 \mathrm{C}$ & $26,10 \pm 2,80 \mathrm{~A}$ & \\
\hline
\end{tabular}

( \pm , standart hataların ortalamasidir.)

Çimlenme ortamında şekerin metabolik enerji kaynağı ve ozmotik düzenleyici olarak rolü büyüktür (O'Kelly, 1955; Vasil, 1964). Çiçek tozlarının çimlenme gücüne besi ortamının şeker içeriği etkilidir. Nar çeşitlerinin çiçeklerinde en güçlü çimlendirme ortamı olarak \%20 şeker içeren besi ortamı belirlenmiştir (Josan ve ark., 1980). Gözlekçi ve Kaynak (2000), steril çiçeklerin çiçek tozu canlılıklarının fertil çiçeklerden daha yüksek olduğunu 
belirlemişlerdir. Engin ve ark. (2015), farklı nar çeşitlerinin steril ve fertil çiçeklerinden alınan çiçek tozlarının çimlenme oranını \%20,4 ile \%43,3 arasında değiştiğini saptamıştır. $\mathrm{Bu}$ çalışmada farklı nar çeşitlerinin steril, ara form ve fertil çiçeklerinin çiçek tozlarının en güçlü çimlenme yeteneğinin steril çiçeklerde olduğu belirlenmiştir.

\section{Sonuç}

Deneme sonuncunda 'Mayhoş 8', 'Katırbaşı', 'Yufkakabuk' ve 'Aşınar' çeşitlerinin steril, fertil ara form çiçeklerin polenlerinin çimlenme güçleri incelendiğinde steril çiçeklerin çimlenme gücünün ara form ve fertil çiçeklerden daha fazla olduğu saptanmıştır. Nar ağaçlarında çiçeklenme farklı zamanlarda gerçekleştiğinden, aynı ağaç ya da farklı ağaç üzerindeki çiçeklerin tozlanması eşit zamanda olmaz. Steril çiçeklerin çiçek tozları aynı ağaçlardaki ya da farklı ağaçlardaki fertil ve ara form çiçeklerin tozlanmasında etkilidir. $\mathrm{Bu}$ nedenle steril çiçeklerin polen tozu çimlenme gücü tozlanmada önemli rol oynar.

Meyve bağlayan steril ve ara form çiçeklerin sayısı verimi etkilemektedir. Steril çiçeklerin çiçek tozu çimlenme gücü yüksek olması avantajlı olsa da nar ağaçlardaki steril çiçek sayısının fazla olması verimi azaltır. Farklı yönden incelendiğinde fertil ve ara form çiçekler açıldığı dönemde erkek çiçekler açmamış ise fertil ve ara form çiçeklerin polenleri tozlanmayı sağlar. Nar ağaçlarının verimli olabilmesi için çiçek tozu çimlenme oranı \%30'un üstünde olmalıdır. Uygulamada yer alan çeşitlerin tümünde ortalama çiçek tozu çimlenme oranı bu verilen yüzdenin altında bulunmuştur. Steril çiçeklerin çimlenme gücü iyi bir verim için tatmin edici değildir. Araştırmada yer alan nar çeşitlerinin çiçek tozu çimlenme gücü daha fazla olan nar çeşitleri ile birlikte yetiştirilmesi önerilmektedir. 


\section{Kaynakça}

Engin H., Hepaksoy S., 2003. Bazı Nar Çeşitlerinin Çiçek Tozu Çimlenme Güçlerinin Belirlenmesi. Ege Üniv. Ziraat Fak. Derg. 40 (3): 9-16.

Engin H., Gökbayrak Z., Altunbaş D., 2015. Epibrassinolid, Gibberellik Asit ve Naftalen Asetik Asittin Bazı Nar Çeşitlerinde Çiçek Tozu Çimlenme Oranlarına Etkisi. Çanakkale Onsekiz Mart Üniversitesi Ziraat Fakültesi Dergisi 3 (2): 19-25.

Eti S., 1991. Bazı Meyve Tür ve Çeşitlerinde Değişik İn Vitro Testler Yardımıyla Çiçek Tozu Canlılık ve Çimlenme Yeteneklerinin Belirlenmesi. Ç.Ü. Ziraat Fakültesi Dergisi. 6 (1): $69-80$.

Gökbayrak Z., Engin H., 2015. Effect of plant growth regulators on enhancing in vitro pollen germination in grapevine cultivars. Third Balkan Symposium on Fruit Growing, 15-18 Eylül 2015. Belgrad, Sirbistan.

Gözlekçi S., Kaynak L., 2000. Investigations on Pollen Production and Quality in Some Standards Pomegranate (Punica granatum L.) Cultivars. Options No: 42: 71-78.

Hewitt F.R., Hough T., O’Neill P., Sasse J.M., Williams E.G., Rowon K.S., 1985. Effect of brassinolide and other growth regulators on the germination and growth of pollen tubes of Prunus avium using a multiple hanging-drop assay. Aust. J. Plant Physiol. 12: 201211.

Josan J.S., Jawanda J.S., Uppal D.P., 1980. Studies on The Floral Biology of Pomegranate. II. Anthesis, Dehiscence, Polen Studies and Receptivity of Stigma. Punjab Horticultural Journal, 19 (1-2): 66-70.

Malgarejo P., Martinez J.J., Hernandez F., 2000. A Study of Different Culture Media for Pomegranate (Punica granatum L.) Pollen. Options No: 42: 63-69.

O’Kelly J.C., 1955. External Carbohydrates in Growth and Respiration of Pollen Tubes "In Vitro". American Journal of Botany, 42 (3): 322-326.

Varasteh F., Arzani K., 2009. Classification of Some Iranian Pomegranate (Punica Granatum) Cultivars by Pollen Morphology Using Scanning Electron Microscopy. Hort. Environ. Biotechnol. 50 (1): 24-30. 
Vasil I.K., 1964. Effect of Boron on Pollen Germination and Pollen Tube Growth. In: Pollen Physiology and Fertilization, Linkens, H.F. (Ed.) North-Holland Publishing Company, Amsterdam, Pp. 107-119.

Viti R., Bartolini S., Vitagliano C., 1990. Growth Regulators on Pollen Germination in Olive. Acta Hort. 286: 227-230.

Wetzstein H.Y., Ravid N., Wilkins E., Martinelli A.P., 2011. A Morphological and Histological Characterization of Bisexual and Male Flower Types in Pomegranate J. Amer. Soc. Hort. Sci. 136 (2): 83-92. 